\title{
The Structure and Magnetic Properties of Rapidly Quenched $\mathrm{Fe}_{72} \mathrm{Ni}_{8} \mathrm{Nb}_{4} \mathrm{Si}_{2} \mathrm{~B}_{14}$ Alloy
}

\author{
Lukasz Hawelek $^{1, *(1)}$, Tymon Warski ${ }^{1}{ }^{10}$, Patryk Wlodarczyk ${ }^{1}$, Marcin Polak ${ }^{1}$, Przemyslaw Zackiewicz ${ }^{1}$, \\ Wojciech Maziarz ${ }^{2}$, Anna Wojcik ${ }^{2}$, Magdalena Steczkowska-Kempka ${ }^{1}$ and Aleksandra Kolano-Burian ${ }^{1}$ \\ 1 Lukasiewicz Research Network-Institute of Non-Ferrous Metals, 5 Sowinskiego str., 44-100 Gliwice, Poland; \\ tymon.warski@imn.gliwice.pl (T.W.); patryk.wlodarczyk@imn.gliwice.pl (P.W.); \\ marcin.polak@imn.gliwice.pl (M.P.); przemyslaw.zackiewicz@imn.gliwice.pl (P.Z.); \\ magdalena.steczkowska-kempka@imn.gliwice.pl (M.S.-K.); olak@imn.gliwice.pl (A.K.-B.) \\ 2 Institute of Metallurgy and Materials Science, Polish Academy of Sciences, 25 Reymonta str., 30-059 Krakow, \\ Poland; w.maziarz@imim.pl (W.M.); wojcik.a@imim.pl (A.W.) \\ * Correspondence: lukaszh@imn.gliwice.pl
}

Citation: Hawelek, L.; Warski, T.; Wlodarczyk, P.; Polak, M.; Zackiewicz, P.; Maziarz, W.; Wojcik, A.; SteczkowskaKempka, M.; Kolano-Burian, A. The Structure and Magnetic Properties of Rapidly Quenched $\mathrm{Fe}_{72} \mathrm{Ni}_{8} \mathrm{Nb}_{4} \mathrm{Si}_{2} \mathrm{~B}_{14}$ Alloy. Materials 2021, 14, 5. https://dx. doi.org/10.3390/ma14010005

Received: 30 October 2020

Accepted: 17 December 2020

Published: 22 December 2020

Publisher's Note: MDPI stays neutral with regard to jurisdictional claims in published maps and institutional affiliations.

Copyright: () 2020 by the authors. Licensee MDPI, Basel, Switzerland. This article is an open access article distributed under the terms and conditions of the Creative Commons Attribution (CC BY) license (https: / / creativecommons.org/ licenses/by/4.0/).

\begin{abstract}
The complex structural and magnetic studies of the annealed rapidly quenched $\mathrm{Cu}$-free $\mathrm{Fe}_{72} \mathrm{Ni}_{8} \mathrm{Nb}_{4} \mathrm{Si}_{2} \mathrm{~B}_{14}$ alloy (metallic ribbons form) are reported here. Based on the calorimetric results, the conventional heat treatment process (with heating rate $10{ }^{\circ} \mathrm{C} / \mathrm{min}$ and subsequent isothermal annealing for $20 \mathrm{~min}$ ) for wound toroidal cores has been optimized to obtain the least lossy magnetic properties (for the minimum value of coercivity and magnetic core losses at $50 \mathrm{~Hz}$ ). For optimal conditions, the complex permeability in the $10^{4}-10^{8} \mathrm{~Hz}$ frequency range together with core power losses obtained from magnetic induction dependence up to the frequency of $400 \mathrm{kHz}$ was successfully measured. The average and local crystal structure was investigated by the use of the X-ray diffraction method and the transmission electron microscopy observations and proved its fully glassy state. Additionally, for the three temperature values, i.e., 310,340 and $370{ }^{\circ} \mathrm{C}$, the glass relaxation process study in the function of annealing time was carried out to obtain a deeper insight into the soft magnetic properties: magnetic permeability and cut-off frequency. For this type of $\mathrm{Cu}$-free soft magnetic materials, the control of glass relaxation process (time and temperature) is extremely important to obtain proper magnetic properties.
\end{abstract}

Keywords: soft magnetic materials; metallic glass; crystallization; magnetic properties

\section{Introduction}

Soft magnetic materials (SMMs) are still of great interest in motor [1], power converter [2,3], switched-mode power supplies [4] and sensor applications [5]. Currently, amorphous and nanocrystalline Fe-, Co- and Ni-based alloys (or combination of ferromagnetic metals) can be used for this purpose [6-9]. There are two main approaches in developing and optimizing of novel SMMs. The first one is aimed at maximizing saturation induction $\left(\mathrm{B}_{\mathrm{s}}\right)$, while the second one in minimizing coercivity $\left(\mathrm{H}_{\mathrm{c}}\right)$ and core losses $\left(\mathrm{P}_{\mathrm{s}}\right)$. The FeCo- and Co-based alloys are reported to have very high induction saturation, good thermal stability and improved mechanical properties. Unfortunately, Co is relatively expensive and is classified as a critical material [10]. It was also recently found that only alloys with low Co content can have good soft-magnetic properties such as low $\mathrm{H}_{\mathrm{c}}$ and high effective permeability $\left(\mu_{\mathrm{e}}\right)[11,12]$. FeNi-based SMMs are a newer class of materials for perspective application at higher frequencies for motors and converters, in which the most important advantage is extremely low coercivity and core losses value, as it was shown in the previous studies $[13,14]$. In these studies, the structural and magnetic properties of the $\mathrm{Cu}$-free $\left(\mathrm{Fe}_{100-x} \mathrm{Ni}_{\mathrm{x}}\right)_{80} \mathrm{Nb}_{4} \mathrm{Si}_{2} \mathrm{~B}_{14}$ alloys were investigated. The magnetization measurements performed on heat-treated samples shown that $B_{\mathrm{s}}$ value is decreasing almost linearly from $1.6 \mathrm{~T}$ for $\mathrm{Ni}=10$ at. $\%$ to $0.75 \mathrm{~T}$ for $\mathrm{Ni}=70$ at.\% content. The Curie temperature of 
as-cast ribbons is increasing from $320^{\circ} \mathrm{C}$ for $\mathrm{Ni}=10$ at. $\%$ up to $400{ }^{\circ} \mathrm{C}$ for $\mathrm{Ni}=30$ at. $\%$ and then it is decreasing for higher Ni content alloys. The Curie point was found to be lower than the temperature of primary crystallization peak observed by calorimetry. However, K. Suzuki et al. in 2001 [15] showed that nanocrystallization of the Cu-free Fe-Nb-B alloys is most likely caused by a high homogenous nucleation rate in the supercooled liquid regime as well as a delayed growth rate induced by a large redistribution of $\mathrm{Nb}$. Additionally, the most present study shows that for $\mathrm{Cu}$-free alloys the lowest value of $\mathrm{H}_{\mathrm{c}}$ exists before the nanocrystallization in the so called "stress relief" stage [16]. Therefore, the detailed studies of crystalline structure and magnetic properties evolution in the function of annealing temperature $\left(\mathrm{T}_{\mathrm{a}}\right)$ for $\mathrm{Cu}$-free FeNi-based alloys are of great importance.

In the present work, the complex structural and magnetic study of $\mathrm{Fe}_{72} \mathrm{Ni}_{8} \mathrm{Nb}_{4} \mathrm{Si}_{2} \mathrm{~B}_{14}$ amorphous alloy are presented. Thermal stability, structure and nanostructure evolution of annealed samples are examined by the use of differential scanning calorimetry (DSC), X-ray diffraction (XRD) and transmission electron microscopy (TEM) observations. Magnetic parameters were obtained by measurements of $\mathrm{B}(\mathrm{H})$ hysteresis loops, $\mathrm{H}_{\mathrm{c}}, \mathrm{B}_{\mathrm{s}}$, core losses $\left(\mathrm{P}_{\mathrm{S}}\right)$, complex permeability $\mu$ and $\mathrm{P}_{\mathrm{s}}$ in the frequency range $(50 \mathrm{~Hz}-400 \mathrm{kHz})$. Additionally, the controlled aging process at three different temperatures has been performed to verify the magnetic permeability and cut-off frequencies as a function of annealing time.

\section{Materials and Methods}

Precursors for amorphous $\mathrm{Fe}_{72} \mathrm{Ni}_{8} \mathrm{Nb}_{4} \mathrm{Si}_{2} \mathrm{~B}_{14}$ alloy were prepared from pure chemical elements $\mathrm{Fe}(3 \mathrm{~N}), \mathrm{Ni}(3 \mathrm{~N}), \mathrm{Si}(4 \mathrm{~N})$ and the binary compounds $\mathrm{FeB}_{18}(2.5 \mathrm{~N}), \mathrm{FeNb}_{65}(2.5 \mathrm{~N})$ using an induction furnace in an argon atmosphere (heating at $1450{ }^{\circ} \mathrm{C}$ for $20 \mathrm{~min}$, casting at $1250{ }^{\circ} \mathrm{C}$ ). The amorphous alloy in the form of ribbons $28 \mu \mathrm{m}$ thick and $6.5 \mathrm{~mm}$ wide by the melt spinning technique (at $30 \mathrm{~m} / \mathrm{s} \mathrm{Cu}$ wheel speed and casting temperature at $1250{ }^{\circ} \mathrm{C}$ ). To achieve the optimal magnetic parameters (min. value of $\mathrm{H}_{\mathrm{c}}$ and $\mathrm{P}_{\mathrm{s}}$ at $50 \mathrm{~Hz}$ and $B=1 T$ ), the toroidal cores (inner and outer diameter of 20 and $30 \mathrm{~mm}$, respectively) were isothermally annealed for $20 \mathrm{~min}$ in a vacuum furnace $\left(5 \cdot 10^{-4} \mathrm{mbar}\right)$ at different temperatures (from 340 to $440{ }^{\circ} \mathrm{C}$ ). Additionally, the effect of aging at three different temperatures: 310,340 and $370{ }^{\circ} \mathrm{C}$ (far below the crystallization temperature) for up to $6200 \mathrm{~min}$ has been checked and the evolution of magnetic permeability and cut-off frequency have been monitored. The amorphousness of the as-spun and annealed ribbons were studied by X-ray diffraction (XRD) at room temperature using Rigaku MiniFlex 600 diffractometer (Rigaku, Tokyo, Japan) equipped with copper tube $\mathrm{CuK} \alpha$. The crystallization processes have been monitored by the differential scanning calorimetry (DSC) with a heating rate of $5-30{ }^{\circ} \mathrm{C} / \mathrm{min}$ using thermal analyzer Netzsch 404C Pegasus (NETZSCH-Gerätebau GmbH, Selb, Germany). The transmission electron microscopy (TEM) images in the bright-field (BF) mode and selected area diffraction patterns (SADPs) were recorded using Tecnai G2 F20 (200kV) electron microscope (Thermo Fisher Scientific, Waltham, MA, USA). Thin foils for TEM observations were prepared with TenuPol-5 double jet electropolisher using an electrolyte of perchloric acid (80\%) and methanol $(20 \%)$ at temperature near $-20{ }^{\circ} \mathrm{C}$. The Remacomp C-1200 (MAGNET-PHYSIK Dr. Steingroever GmbH, Köln, Germany) magnetic measurement system was used to determine $\mathrm{B}(\mathrm{H})$ and $\mathrm{P}_{\mathrm{s}}$. The complex magnetic permeability in the frequency (f) range $10^{4}-10^{8} \mathrm{~Hz}$ at room temperature of the toroidal cores was measured using impedance analyzer Agilent 4294A (Agilent, Santa Clara, CA, USA).

\section{Result and Discussion}

For melt-spun ribbon, the $\alpha$-Fe type phase crystallization kinetics has been studied by use of the differential scanning calorimetry (DSC) by performing measurements with heating rates in the range from 5 to $30^{\circ} \mathrm{C} / \mathrm{min}$. Obtained DSC curves have been plotted in Figure 1a. The onset temperature of crystallization peak varies from $479.7^{\circ} \mathrm{C}$ for heating rate $5^{\circ} \mathrm{C} / \mathrm{min}$ up to $500.7^{\circ} \mathrm{C}$ for heating rate $30^{\circ} \mathrm{C} / \mathrm{min}$. For such non-isothermal 
crystallization processes, the Kissinger model [17] was used to determine the average activation energy. This method is based on the equation:

$$
\ln \left(\frac{\phi}{T_{p}^{2}}\right)=\ln \left(\frac{A_{0} R}{E_{a}}\right)-\frac{E_{a}}{\left(R T_{p}\right)},
$$

where $\phi$ is a heating rate, $T_{p}$-the temperature of the crystallization peak, $E_{a}$-activation energy, $R$-gas constant and $A_{0}$ - pre-exponential factor. By linear fitting of $\ln \left(\frac{\phi}{T_{p}^{2}}\right)$ vs. $\frac{1}{T_{p}}$ curve the average activation energy $E_{a}$ of the process has been determined from the slope of this curve (Figure 1b). The obtained average activation energy $E_{a}$ of crystallization of the $\alpha$-Fe is equal to $430.2 \pm 6.5 \mathrm{~kJ} / \mathrm{mol}$. Crystallization peaks were also fitted to the Avrami equation:

$$
\ln (-\ln [1-\alpha(t)])=\ln (k)+n \ln (t)
$$

where: $\alpha(\mathrm{t})$-degree of crystallization, $\mathrm{k}$-crystallization rate constant, $\mathrm{n}$-Avrami constant, $\mathrm{t}$ - time. All the Avrami fits were conducted in the 30-70\% range of the degree of crystallization and gathered in Figure $1 \mathrm{~b}$. From the Avrami fits, average $\mathrm{n}$ index describing the mechanism of crystallization was derived. It is equal to $2.5 \pm 0.2$. According to Malek [18], the kinetic exponent $\mathrm{n}=2.5$ describes the transformation as the diffusion controlled growth process with the constant nucleation rate.

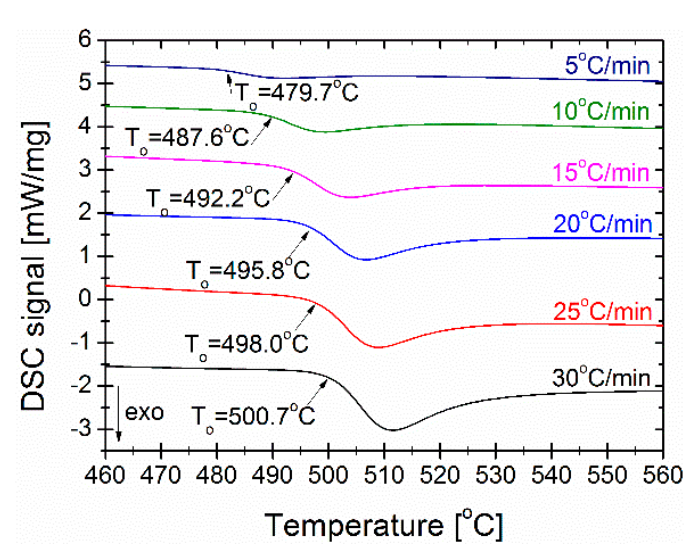

(a)
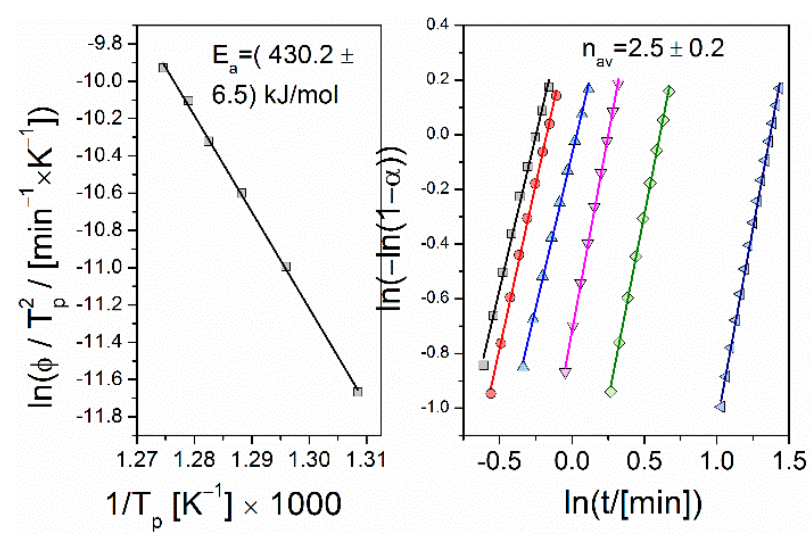

(b)

Figure 1. DSC signals (a), activation energy $E_{a}$ of $\alpha$-Fe phase crystallization and the Avrami exponent $\mathrm{n}(\mathbf{b})$ estimated for as-spun metallic glass (colors defines heating rates as shown in Figure 1a).

In Figure 2, the dependences of the coercivity $\mathrm{H}_{c}$ on the annealing temperature $\mathrm{T}_{\mathrm{a}}$ with the magnetic saturation $B_{s}\left(T_{a}\right)$ Figure $2 a$ and on the core losses $P_{s}\left(T_{a}\right)$ Figure $2 b$ are presented. $\mathrm{H}_{\mathrm{C}}$ and $\mathrm{B}_{\mathrm{s}}$ values were taken from the hysteresis loops measured up to magnetic saturation state. The $\mathrm{H}_{\mathrm{c}}\left(\mathrm{T}_{\mathrm{a}}\right)$ curve shows the minimum value at $\mathrm{T}_{\mathrm{a}}=370{ }^{\circ} \mathrm{C}$ with $\mathrm{H}_{\mathrm{c}}=3.95 \mathrm{~A} / \mathrm{m}$ and $\mathrm{B}_{\mathrm{s}}=1.09 \mathrm{~T}$. Below this temperature $\mathrm{H}_{\mathrm{c}}$ value is decreasing from $5 \mathrm{~A} / \mathrm{m}$ at $340{ }^{\circ} \mathrm{C}$, while above this temperature $\mathrm{H}_{\mathrm{c}}$ value is increasing up to $125 \mathrm{~A} / \mathrm{m}$ at $440{ }^{\circ} \mathrm{C}$. The magnetic saturation is increasing with $\mathrm{T}_{\mathrm{a}}$ from $1.05 \mathrm{~T}$ at $340{ }^{\circ} \mathrm{C}$ up to $1.29 \mathrm{~T}$ at $440{ }^{\circ} \mathrm{C}$. The Bs value at coercivity minimum equals $1.09 \mathrm{~T}$. Obtained $\mathrm{B}_{\mathrm{s}}$ is much lower than presented in [3] for $\mathrm{Fe}_{70} \mathrm{Ni}_{10} \mathrm{Nb}_{4} \mathrm{Si}_{2} \mathrm{~B}_{14}$, but, as was mentioned in the introduction section, authors did not optimize the annealing temperature and didn't measure $\mathrm{H}_{\mathrm{c}}$ and $P_{s}$ values. From an application point of view the knowledge of $H_{c}$ and especially of $P_{S}$ is of the greatest importance. It is clearly seen in Figure 2, that $P_{s}\left(T_{a}\right)$ dependence shape strongly correlates with the $\mathrm{H}_{c}$ one. The minimum value $\mathrm{P}_{\mathrm{s}}=0.092 \mathrm{~W} / \mathrm{kg}$ coexists with a minimum value of $\mathrm{H}_{\mathrm{c}}$ at annealing temperature $\mathrm{T}_{\mathrm{a}}=370{ }^{\circ} \mathrm{C}$. For sample annealed in $\mathrm{P}_{\mathrm{s}}$ minimum (so-called optimal conditions) at $370{ }^{\circ} \mathrm{C}$ the complex magnetic permeability has been measured at room temperature (RT) in order to obtain the level of real $\mu^{\prime}$ and the 
frequency value of imaginary $\mu$ " maximum. Both components are gathered in Figure 3 . The magnetic permeability $\mu^{\prime}$ reaches 3100 in low frequency limit $\left(f=10^{4} \mathrm{~Hz}\right)$ and decreases for higher frequencies, while the maximum value of magnetic permeability loss $\mu^{\prime \prime}$ exists for $\mathrm{f}=5 \cdot 10^{5} \mathrm{~Hz}$. This value is crucial for application purposes and is defined as "cut-off" frequency, the usage frequency of this material $[19,20]$. The next application important value of soft magnetic materials are the $A C$ core power losses $P_{S}$ in the function of $B_{S}$ for the low $(50 \mathrm{~Hz})$ to high $(400 \mathrm{kHz})$ frequencies. This $\log -\log$ dependence is shown in Figure 3. It can be seen that, for all the frequencies, the $P_{S}$ value increases almost linearly with increasing magnetic field strength, mainly because more immense energy is required to increase induction near the saturation [4]. Obtained magnetic properties have been finally collected and compared with the other previously reported FeNi-based soft-magnetic alloys in Table 1. As shown, there are still some gaps in the data on the magnetic properties of classically annealed FeNi-based alloys. Moreover, when using a rapid annealing process, very attractive magnetic properties must be obtained.

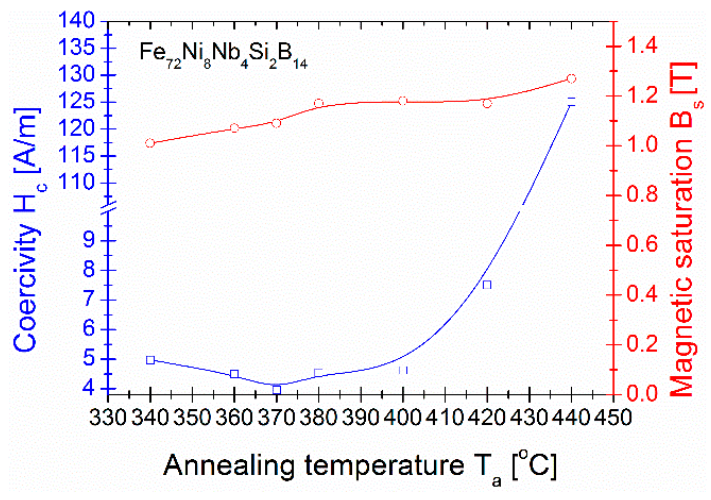

(a)

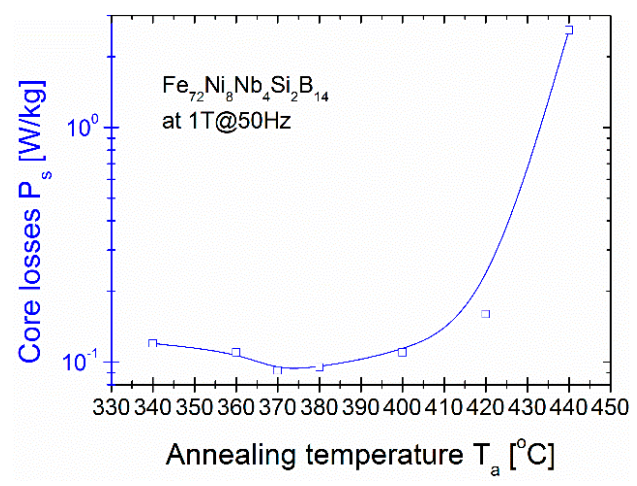

(b)

Figure 2. $\mathrm{H}_{\mathrm{c}}$ and $\mathrm{B}_{\mathrm{S}}$ from $\mathrm{T}_{\mathrm{a}}(20 \mathrm{~min})(\mathbf{a})$ and $\mathrm{P}_{\mathrm{s}}$ from $\mathrm{T}_{\mathrm{a}}(\mathbf{b})$ dependences. The lines are only guide for eyes and not a fit.

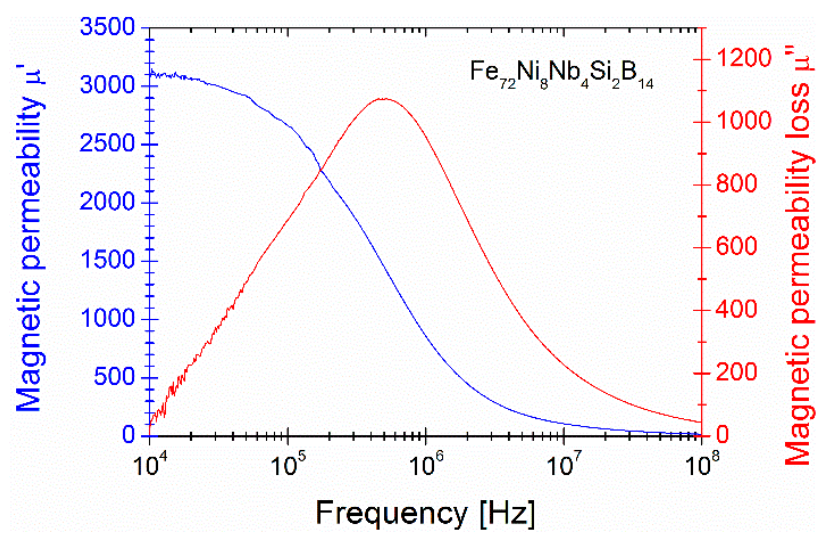

(a)

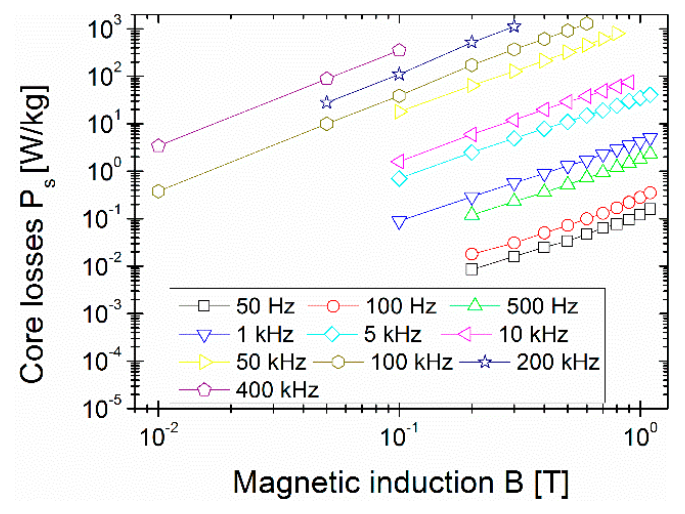

(b)

Figure 3. Magnetic permeability $\mu^{\prime}$ (a) and magnetic permeability loss $\mu^{\prime \prime}$ (b) dependence in the function of frequency $10^{4}-10^{8} \mathrm{~Hz}$ for sample annealed at $370{ }^{\circ} \mathrm{C}$. 
Table 1. Comparison the magnetic properties of various FeNi-based alloys with obtained results.

\begin{tabular}{|c|c|c|c|c|c|c|c|}
\hline Alloy & Ta $\left[{ }^{\circ} \mathrm{C}\right] /$ time & Ps $[W / k g]$ & $\begin{array}{l}\text { Bs } \\
{[\mathrm{T}]}\end{array}$ & $\mathrm{Hc}[\mathrm{A} / \mathrm{m}]$ & $\mu^{\prime}$ & $\mathbf{f}_{\text {cut-off }}[\mathrm{kHz}]$ & Ref \\
\hline $\mathrm{Fe}_{72} \mathrm{Ni}_{8} \mathrm{Nb}_{4} \mathrm{Si}_{2} \mathrm{~B}_{14}$ & $370 / 20 \mathrm{~min}$ & $P_{10 / 50}=0.092$ & 1.09 & 3.95 & 3100 & 507 & This work \\
\hline $\mathrm{Fe}_{72} \mathrm{Ni}_{8} \mathrm{Nb}_{4} \mathrm{Si}_{2} \mathrm{~B}_{14}$ & $440 / 20 \mathrm{~min}$ & $\mathrm{P}_{10 / 50}=2.6$ & 1.29 & 125 & - & - & This work \\
\hline $\mathrm{Fe}_{70} \mathrm{Ni}_{10} \mathrm{Nb}_{4} \mathrm{Si}_{2} \mathrm{~B}_{14}$ & as-cast & 1070 & $\sim 1.62$ & - & - & - & [13] \\
\hline $\mathrm{Fe}_{60} \mathrm{Ni}_{20} \mathrm{Nb}_{4} \mathrm{Si}_{2} \mathrm{~B}_{14}$ & as-cast & - & $\sim 1.44$ & - & - & - & [13] \\
\hline $\mathrm{Fe}_{56} \mathrm{Ni}_{24} \mathrm{Nb}_{4} \mathrm{Si}_{2} \mathrm{~B}_{14}$ & $440 / 60 \mathrm{~min}$ & $P_{1060}=0.12$ & $\sim 1.1$ & 7 & 4000 & - & [14] \\
\hline $\mathrm{Fe}_{56} \mathrm{Ni}_{24} \mathrm{Nb}_{4} \mathrm{Si}_{2} \mathrm{~B}_{14}$ & $\begin{array}{l}440 / 60 \mathrm{~min} \\
200 \mathrm{MPa}\end{array}$ & - & 1.3 & - & 16,000 & - & [14] \\
\hline $\mathrm{Fe}_{77.4} \mathrm{Ni}_{8.6} \mathrm{~B}_{14}$ & $\mathrm{RA}^{*} 490 / 0.5 \mathrm{~s}$ & - & 1.7 & 2.6 & - & - & [21] \\
\hline $\mathrm{Fe}_{68.8} \mathrm{Ni}_{17.2} \mathrm{~B}_{14}$ & $\mathrm{RA}^{*} 510 / 0.5 \mathrm{~s}$ & - & 1.54 & 4.4 & - & - & [21] \\
\hline $\mathrm{Fe}_{60.2} \mathrm{Ni}_{25.8} \mathrm{~B}_{14}$ & $\mathrm{RA}^{*} 510 / 0.5 \mathrm{~s}$ & - & 1.37 & 3.2 & - & - & [21] \\
\hline
\end{tabular}

${ }^{*} \mathrm{RA}-$ Rapid Annealing with heating rate of $10^{4} \mathrm{~K} / \mathrm{s}$.

As was shown by Yoshizawa [22], small additions of $\mathrm{Cu}$ and $\mathrm{Nb}$ facilitate the formation of an amorphous-crystalline nanocomposite microstructure upon annealing of initially amorphous precursor materials. For the $\mathrm{Cu}$-free and $\mathrm{Nb}$-containing alloy, as we study in this work- $\mathrm{Fe}_{72} \mathrm{Ni}_{8} \mathrm{Nb}_{4} \mathrm{Si}_{2} \mathrm{~B}_{14}$ - the $\mathrm{Nb}$ atoms play commonly a diffuse role towards the surrounding amorphous matrix and increase the thermal stability of the matrix. The XRD patterns of annealed samples gathered in Figure 4 prove that, for temperature annealing up to $400{ }^{\circ} \mathrm{C}$ for $20 \mathrm{~min}$, the crystal structure remains amorphous and only first and second-order diffused amorphous halos exist on the patterns. For annealed sample at $\mathrm{T}_{\mathrm{a}}=420^{\circ} \mathrm{C}$, the three small diffraction peaks are visible and correspond to the $\alpha$-Fe phase, while for $\mathrm{T}_{\mathrm{a}}=440{ }^{\circ} \mathrm{C}$ these peaks are of higher intensity. The TEM observations in BF mode (Figure 5a,c) and SADPs (Figure 5b,d) for samples annealed at 370 and $420^{\circ} \mathrm{C}$, respectively, proved the amorphous state of the annealed sample at $370{ }^{\circ} \mathrm{C}$ and presence of $\sim 10-30 \mathrm{~nm}$ $\alpha$-Fe nanocrystals in the second one. Based on the TEM observations, it can be seen that, for a sample with optimal magnetic properties (e.g., the lowest $P_{s}$ ), the crystal structure in the nano scale remains in the amorphous state.

Aging of metallic glasses is caused by the annealing process. Structural relaxation linked with quenched-in stress elimination is associated with the improvement of the magnetic properties of the soft magnetic amorphous ribbon. From the point of view of the crystal structure, aging in metastable quenched metallic glasses induces a lower enthalpy, a smaller volume, a more stable glassy state and changes the topological short-range order, which is characteristic for the glass structure [23-28] Some of the previous studies have shown that the relaxation process of $\mathrm{FeNiSiB}$ systems can be divided into two stages: the first - metalloid atoms movement, the second-diffusion of the constituent atoms [29]. From the magnetic point of view, the elimination of internal stresses can improve the mobility of the Bloch wall of the magnetic domain [30] and, as a consequence, the magnetic anisotropy fluctuates during the change of the topological short-range order caused by the aging/rejuvenation process [31]. As the relative permeability is inversely proportional to the anisotropy constant, the magnetic saturation increases with the local structure change and the decrease in anisotropy constant [32]. Thus, based on the above and on the fact that optimal annealing conditions (in the context of minimum $\mathrm{H}_{\mathrm{c}}$ and $\mathrm{P}_{\mathrm{S}}$ value) are treatment at $370{ }^{\circ} \mathrm{C}$ for $20 \mathrm{~min}$ and the material is still in the glassy state, further verification of the annealing process in the glassy state has been performed also at lower temperatures: 310 , 340 and $370{ }^{\circ} \mathrm{C}$, with different annealing times up to $6200 \mathrm{~min}$. As has been shown in Figure 6 the $\mu^{\prime}$ value increases substantially from 3100 obtained for 20 min of annealing up to over 4500 for annealing time in the range 200-2000 min. Interestingly, for lower annealing temperature $\mathrm{T}_{\mathrm{a}}=340{ }^{\circ} \mathrm{C} \mu^{\prime}$ consequently increases with annealing time and reaches 5000 for $6200 \mathrm{~min}$. Process of glass relaxation is much weaker for Ta $=310^{\circ} \mathrm{C}$ and for the annealing time up to $6200 \mathrm{~min} \mu^{\prime}$ slightly increases. It has been noted that the relaxation process is still not complete. The cut-off frequency for Ta dependence indicates 
how the annealing process affects the $\mu^{\prime \prime}$ peak position that may be correlated with the reorganization of the magnetic domains during glass relaxation [30]. The downward trend in the cut-off frequency suggest that slow reorganization of the local structure occurs during aging process and some $\alpha$-Fe clusters may form and grow. As was shown here, from the energy point of view, for lower temperature $\left(340^{\circ} \mathrm{C}\right)$ i.e., when less energy is delivered to the glass system, a slower relaxation process takes place and a higher permeability value in relaxed glass can be achieved. Considering the stability of cut-off frequency parameter, the most stable (invariant) annealing temperature is $370^{\circ} \mathrm{C}$ and there are no significant changes in the annealing time up to $6200 \mathrm{~min}$. This is crucial from the application point of view and needs to be investigated more closely soon. For all the samples after such aging process the XRD measurements proved the amorphous state of the samples (see Figure 7). As it was shown in some recent papers [33-36], the APT (Atom Probe Tomography) together with MOKE (Magneto-Optic Kerr Effect) and in situ AFM (Atomic Force Microscopy) observations should give us a more precise explanation of the glass relaxation process and early stage of the nucleation process in the studied system. The APT should give us the information on $\mathrm{Fe}, \mathrm{Ni}$ as well as $\mathrm{B}$, Si partitioning in the glassy state during long-term aging and moment of initial state of crystallization, while MOKE\&AFM will allow to monitor the surface magnetic properties and morphology changes induced by relaxation process.

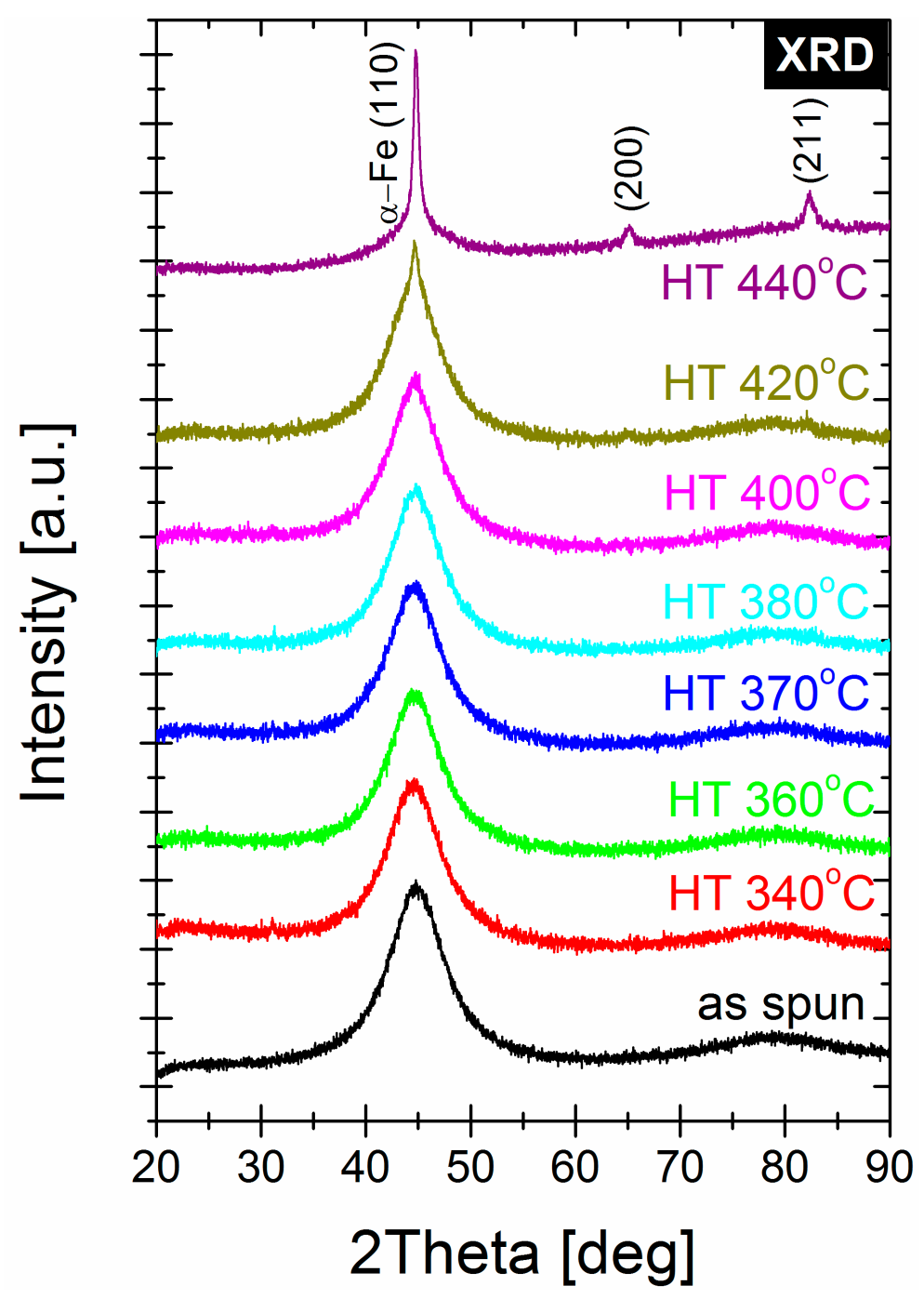

Figure 4. XRD patterns for annealed samples. 


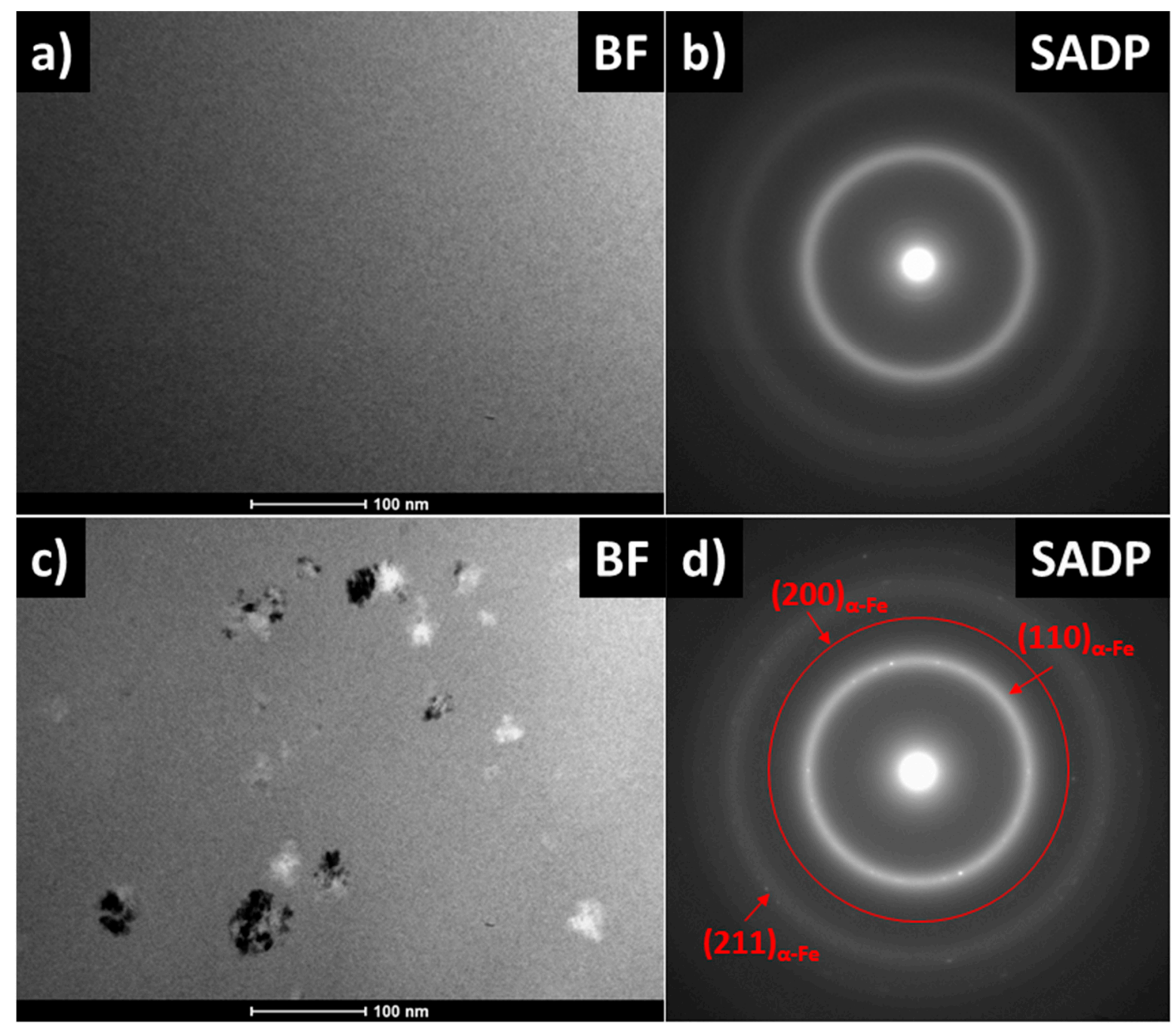

Figure 5. TEM images for annealed samples: (a) BF at $370{ }^{\circ} \mathrm{C}$ (b) SADP at $370{ }^{\circ} \mathrm{C}$ (c) BF at $420{ }^{\circ} \mathrm{C}$ (d) Scheme $420{ }^{\circ} \mathrm{C}$.

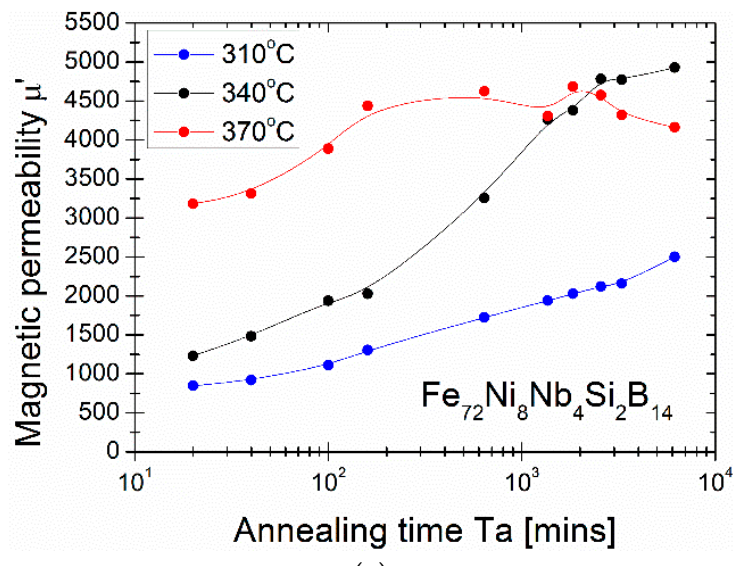

(a)

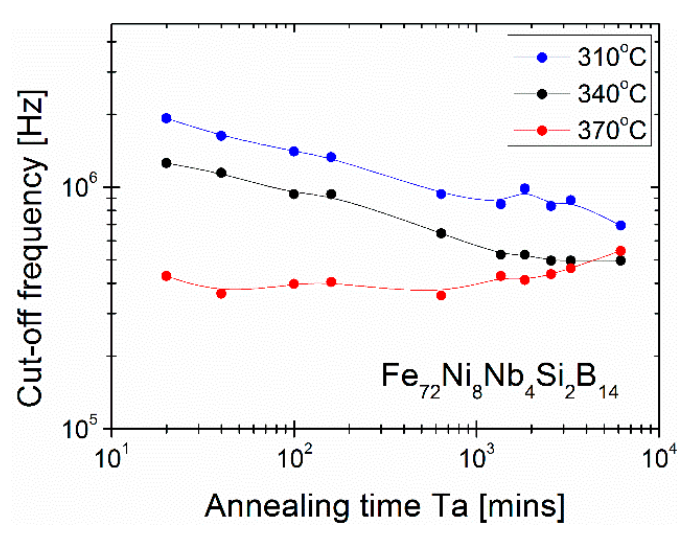

(b)

Figure 6. Magnetic permeability (a) and cut-off frequency (b) dependencies on annealing time performed at $310{ }^{\circ} \mathrm{C}, 340{ }^{\circ} \mathrm{C}$ and $370{ }^{\circ} \mathrm{C}$. The lines are only guide for eyes and not a fit. 


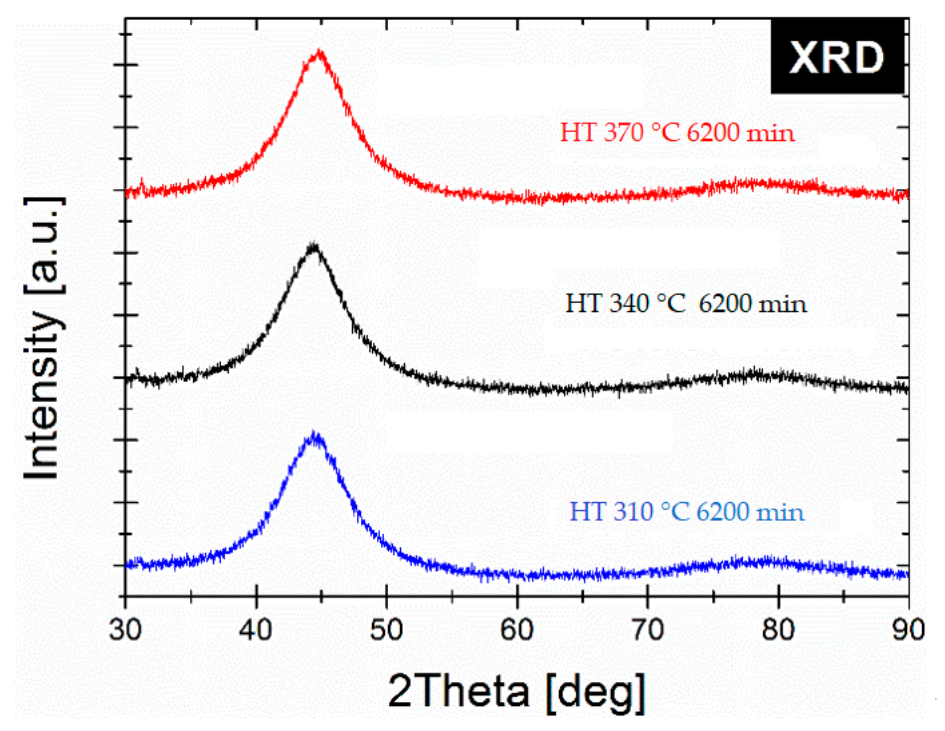

Figure 7. XRD patterns for relaxed glasses after $6200 \mathrm{~min}$.

\section{Conclusions}

The structural and magnetic properties of the conventionally annealed $\mathrm{Fe}_{72} \mathrm{Ni}_{8} \mathrm{Nb}_{4} \mathrm{Si}_{2} \mathrm{~B}_{14}$ alloy prepared by melt spinning have been investigated. The deep insight into the correlation between the magnetic properties $\mathrm{B}_{\mathrm{s}}, \mathrm{H}_{\mathrm{c}}, \mathrm{P}_{\mathrm{s}}$ and $\mathrm{T}_{\mathrm{a}}$ allowed to determine the optimal conditions. For the $\mathrm{T}_{\mathrm{a}}=370{ }^{\circ} \mathrm{C}$, minimum value of $\mathrm{H}_{\mathrm{c}}$ of $3.95 \mathrm{~A} / \mathrm{m}, \mathrm{P}_{10 / 50}$ of $0.092 \mathrm{~W} / \mathrm{kg}$, $\mathrm{B}_{\mathrm{S}}=1.09 \mathrm{~T}, \mu^{\prime}$ of 3100 and cut-off frequency of $5 \times 10^{5} \mathrm{~Hz}$ have been obtained. That is over $100{ }^{\circ} \mathrm{C}$ below the crystallization onset temperature obtained from the DSC study. The $\mathrm{P}_{\mathrm{s}}$ (B) dependence has been also shown and the optimal annealed material possess the linear $\mathrm{P}_{\mathrm{S}}$ (B) dependence up to $400 \mathrm{kHz}$. The structural study has shown that, for such optimal conditions, material remains in the glassy state; the so-called relaxed glassy state. Deeper insight into the relaxation process occurring during the aging of this metallic glass shown that is possible to get higher $\mu^{\prime}$ values for longer annealing (over $100 \mathrm{~h}$ ) time even at lower temperature $\mathrm{T}_{\mathrm{a}}=340{ }^{\circ} \mathrm{C}$. However, the optimal $\mathrm{T}_{\mathrm{a}}=370{ }^{\circ} \mathrm{C}$ is the most stable from the point of view of the stability of cut-off frequency value.

Author Contributions: Conceptualization, L.H. and A.K.-B.; investigation, T.W., P.W., M.P., P.Z., W.M., A.W., M.S.-K. and L.H.; writing—original draft preparation, L.H. and P.W.; writing—review and editing, L.H. and P.W.; supervision, L.H. All authors have read and agreed to the published version of the manuscript.

Funding: This work was financed by the National Centre for Research and Development Grant TECHMATSTRATEG No. 1/347200/11/NCBR/2017.

Institutional Review Board Statement: Not applicable.

Informed Consent Statement: Not applicable.

Data Availability Statement: The data presented in this study are available on request from the corresponding authors.

Conflicts of Interest: The authors declare no conflict of interest. The funders had no role in the design of the study; in the collection, analyses, or interpretation of data; in the writing of the manuscript, or in the decision to publish the results.

\section{References}

1. Simizu, S.; Ohodnicki, P.R.; McHenry, M.E. Metal amorphous nanocomposite soft magnetic material-enabled high power density, rare earth free rotational machines. IEEE Trans. Magn. 2018, 54, 1-5. [CrossRef]

2. Leary, A.M.; Ohodnicki, P.R.; McHenry, M.E. Soft magnetic materials in high-frequency, high-power conversion applications. JOM 2012, 64, 772-781. [CrossRef]

3. Mazaleyrat, F.; Varga, L.K. Ferromagnetic nanocomposites. J. Magn. Magn. Mater. 2000, 215, 253-259. [CrossRef] 
4. Willard, M.A. Nanocrystalline Soft Magnetic Alloys: Two Decades of Progress. Handb. Magn. Mater. 2013 21, $173-342$.

5. Kurlyandskaya, G.V.; Shcherbinin, S.V.; Volchkov, S.O.; Bhagat, S.M.; Calle, E.; Pérez, R.; Vazquez, M. Soft magnetic materials for sensor applications in the high frequency range. J. Magn. Magn. Mater. 2018, 459, 154-158. [CrossRef]

6. Huang, D.; Li, Y.; Yang, Y.; Zhu, Z.; Zhang, W. Soft magnetic Co-based Co-Fe-B-Si-P bulk metallic glasses with high saturation magnetic flux density of over 1.2 T. J. Alloy. Compd. 2020, 843, 154862. [CrossRef]

7. Warski, T.; Wlodarczyk, P.; Polak, M.; Zackiewicz, P.; Radon, A.; Wojcik, A.; Szlezynger, M.; Kolano-Burian, A.; Hawelek, L. Influence of $\mathrm{Cu}$ Content on Structure and Magnetic Properties in Fe86-xCuxB14 Alloys. Materials 2020, 13, 1451. [CrossRef]

8. Zhukova, V.; Korchuganova, O.A.; Aleev, A.A.; Tcherdyntsev, V.V.; Churyukanova, M.; Medvedeva, E.V.; Seils, S.; Wagner, J.; Ipatov, M.; Blanco, J.M.; et al. Effect of annealing on magnetic properties and structure of Fe-Ni based magnetic microwires. J. Magn. Magn. Mater. 2017, 433, 278-284. [CrossRef]

9. Sagasti, A.; Palomares, V.; Porro, J.M.; Orue, I.; Sanchez-Ilarduya, M.B.; Lopes, A.C.; Gutierrez, J. Magnetic, Magnetoelastic and Corrosion Resistant Properties of (Fe-Ni)-Based Metallic Glasses for Structural Health Monitoring Applications. Materials 2020, 13, 57. [CrossRef]

10. Jin, Y.; Kim, J.; Guillaume, B. Review of critical material studies. Resour. Conserv. Recycl. 2016, 113, 77-87. [CrossRef]

11. Shen, B.; Inoue, A.; Chang, C. Superhigh strength and good soft-magnetic properties of (Fe, Co)-B-Si-Nb bulk glassy alloys with high glass-forming ability. Appl. Phys. Lett. 2004, 85, 4911-4913. [CrossRef]

12. Amiya, K.; Urata, A.; Nishiyama, N.; Inoue, A. Thermal stability and magnetic properties of (Fe, Co)-Ga-(P, C, B, Si) bulk glassy alloys. Mater. Sci. Eng. A 2007, 449, 356-359. [CrossRef]

13. Aronhime, N.; Zoghlin, E.; Keylin, V.; Jin, X.; Ohodnicki, P.; McHenry, M.E. Magnetic properties and crystallization kinetics of (Fe100- xNix) 80Nb4Si2B14 metal amorphous nanocomposites. Scr. Mater. 2018, 142, 133-137. [CrossRef]

14. Aronhime, N.; DeGeorge, V.; Keylin, V.; Ohodnicki, P.; McHenry, M.E. The effects of strain-annealing on tuning permeability and lowering losses in Fe-Ni-based metal amorphous nanocomposites. JOM 2017, 69, 2164-2170. [CrossRef]

15. Suzuki, K.; Cadogan, J.M.; Aoki, K.; Tsai, A.P.; Inoue, A.; Masumoto, T. Nanocrystallization and glass transition in Cu-Free Fe-Nb-B soft magnetic alloys. Scr. Mater. 2001, 44, 1417-1420. [CrossRef]

16. Liu, T.; Wang, A.; Zhao, C.; Yue, S.; Wang, X.; Liu, C.T. Compositional design and crystallization mechanism of High Bs nanocrystalline alloys. Mater. Res. Bull. 2019, 112, 323-330. [CrossRef]

17. Kissinger, H.E. Reaction kinetics in differential thermal analysis. Anal. Chem. 1957, 29, 1702-1706. [CrossRef]

18. Málek, J. The applicability of Johnson-Mehl-Avrami model in the thermal analysis of the crystallization kinetics of glasses. Thermochim. Acta 1995, 267, 61-73. [CrossRef]

19. Snoek, J.L. Gyromagnetic resonance in ferrites. Nature 1947, 160, 90. [CrossRef] [PubMed]

20. Rozanov, K.N.; Koledintseva, M.Y. Application of generalized Snoek's law over a finite frequency range: A case study. J. Appl. Phys. 2016, 119, 073901. [CrossRef]

21. Li, Z.; Parsons, R.; Zang, B.; Kishimoto, H.; Shoji, T.; Kato, A.; Suzuki, K. Dramatic grain refinement and magnetic softening induced by Ni addition in FeB based nanocrystalline soft magnetic alloys. Scr. Mater. 2020, 181, 82-85. [CrossRef]

22. Yoshizawa, Y.A.; Oguma, S.; Yamauchi, K. New Fe-based soft magnetic alloys composed of ultrafine grain structure. J. Appl. Phys. 1988, 64, 6044-6046. [CrossRef]

23. Komatsu, T.; Matusita, K.; Yokota, R. Volume changes during the structural relaxation and crystallization in FeNi based metallic glasses. J. Non-Cryst. Sol. 1985, 69, 347-359. [CrossRef]

24. Miyazaki, N.; Wakeda, M.; Wang, Y.J.; Ogata, S. Prediction of pressure-promoted thermal rejuvenation in metallic glasses. NPJ Comput. Mater. 2016, 2, 1-9. [CrossRef]

25. Nagel, C.; Rätzke, K.; Schmidtke, E.; Faupel, F.; Ulfert, W. Positron-annihilation studies of free-volume changes in the bulk metallic glass Zr65Al7.5Ni10Cu17.5 during structural relaxation and at the glass transition. Phys. Rev. B 1999, 60, 9212. [CrossRef]

26. Imran, M.M.; Bhandari, D.; Saxena, N.S. Enthalpy recovery during structural relaxation of Se96In 4 chalcogenide glass. Phys $B$ Condens. Matter 2001, 293, 394-401. [CrossRef]

27. Slipenyuk, A.; Eckert, J. Correlation between enthalpy change and free volume reduction during structural relaxation of Zr55Cu30Al10Ni5 metallic glass. Scr. Mater. 2004, 50, 39-44. [CrossRef]

28. Waseda, Y.; Masumoto, T. Structure of amorphous Fe80-P13-C7 alloy by X-ray diffraction. Z. Für. Phys. B Condens. Matter 1975, 22, 121-126. [CrossRef]

29. Miyazaki, T.; Hisatake, K.; Takahashi, M. Magnetic Relaxation in Amorphous (Fe1-xNix)77Si10B13 Alloys. Jpn. J. Appl. Phys. 1983, 22, 1277-1282. [CrossRef]

30. Escobar, M.A.; Yavari, A.R.; Barrue, R.; Perron, J.C. On the optimization of soft-magnetic properties of metallic glasses by dynamic current annealing. IEEE Trans. Magn. 1992, 28, 1911-1916. [CrossRef]

31. Ri, M.C.; Sohrabi, S.; Ding, D.W.; Dong, B.S.; Zhou, S.X.; Wang, W.H. Serrated magnetic properties in metallic glass by thermal cycle. Chin. Phys. B 2017, 26, 066101. [CrossRef]

32. McHenry, M.E.; Laughlin, D.E. Physical Metallurgy; Elsevier: Amsterdam, The Netherlands, 2014; pp. $1881-2008$.

33. Hono, K.; Ping, D.H.; Ohnuma, M.; Onodera, H. Cu clustering and Si partitioning in the early crystallization stage of an Fe73.5Si13.5B9Nb3Cu1 amorphous alloy. Acta Mater. 1999, 47, 997-1006. [CrossRef]

34. Pradeep, K.G.; Herzer, G.; Choi, P.; Raabe, D. Atom probe tomography study of ultrahigh nanocrystallization rates in FeSiNbBCu soft magnetic amorphous alloys on rapid annealing. Acta Mater. 2014, 68, 295-309. [CrossRef] 
35. Shah, M.; Satalkar, M.; Kane, S.N.; Ghodke, N.L.; Sinha, A.K.; Varga, L.K.; Araujo, J.P. Thermal treatment induced modification of structural, surface and bulk magnetic properties of Fe61. 5Co5Ni8Si13. 5B9Nb3 metallic glass. AIP Conf. Proc. 2018, 1953, 120043.

36. McCord, J. Progress in magnetic domain observation by advanced magneto-optical microscopy. J. Phys. D Appl. Phys. 2015, 48, 333001. [CrossRef] 